\title{
FRECUENCIA DE ANTICUERPOS CONTRA Toxoplasma gondii EN MONOS Cebus apella CRIADOS EN CAUTIVERIO
}

\author{
Erich Muñoz D. ${ }^{1}$, Amanda Chávez V. ${ }^{2,3}$ Eva Casas A. ${ }^{2}$, Francisco Suárez A. ${ }^{4}$, \\ César Gavidia Ch. ${ }^{4}$, Karina Muñoz D. ${ }^{5}$ y Federico Gutiérrez $\mathbf{A}^{5}$
}

\section{Abstract}

The purpose of the present study was to determine the frequency of primates (Cebus apella) carrying anti-Toxoplasma gondii antibodies at the zoo of the Patronato del Parque de las Leyendas, in Lima. Sixty two sera samples were obtained and analyzed by the Indirect Hemaglutination test (HAI) to detect antibodies against $T$. gondii. The results showed that $90.3 \%$ (56/62) sera were positive, and no significant asociation due to sex and age (juvenile and adult) were found. The high rate of positive primates to this parasite could be due to the high number of domestics cats in the premises.

Key words : toxoplasmosis, Toxoplasma gondii, indirect hemaglutination, Cebus apella, primate, zoo

\section{RESUMEN}

El presente estudio tuvo como objetivo determinar la frecuencia de portadores de anticuerpos anti-Toxoplasma gondii en primates de la especie Cebus apella en el zoológico del Patronato del Parque de las Leyendas, ubicado en la ciudad de Lima. Se tomaron 62 muestras de suero sanguíneo y se evaluó la presencia de anticuerpos contra T. gondii mediante la prueba de hemaglutinación indirecta (HAI). Se encontró el 90.3\% (56/62) de sueros positivos, sin que hubiera diferencia estadística significativa entre sexo o grupos etáreos (juveniles y adultos). Los resultados mostraron una elevada tasa de primates reactores a este parásito, que puede deberse al elevado número de gatos que transitan libremente en los alrededores de los ambientes asignados a los primates.

Palabras clave: toxoplasmosis, Toxoplasma gondi, hemaglutinación indirecta, Cebus apella, primate, zoológico

\footnotetext{
${ }^{1}$ Práctica privada

${ }^{2}$ Laboratorio de Microbiología y Parasitología Veterinaria, FMV-UNMSM

${ }^{3}$ E-mail: a_chavez_g@hotmail.com

${ }^{4}$ Laboratorio de Medicina Veterinaria Preventiva, FMV-UNMSM

${ }^{5}$ Patronato del Parque de las Leyendas (PATPAL)
} 
INTRODUCCIÓN

El Toxoplasma gondii es un protozoo intracelular que afecta a diferentes especies de animales de sangre caliente, causando en algunos de ellos problemas de tipo sanitario y reproductivo, tales como reabsorción embrionaria, abortos o nacimiento de crías débiles (Atías, 1994). Dentro de las especies más afectadas por este parásito se encuentran los ovinos, camélidos sudamericanos, cerdos, perros y gatos. En el campo de la salud pública, su importancia radica especialmente en personas inmunosuprimidas y mujeres gestantes, donde puede llegar a producir abortos o nacimientos de niños con lesiones oculares o cerebrales. La toxoplasmosis es una de las parasitosis más difundidas a nivel mundial (Acha y Szyfres, 1992).

El T. gondii tiene como hospedero definitivo a los félidos domésticos y silvestres y como hospedero intermediario a un amplio rango de mamíferos y aves. Presenta una fase de reproducción sexual en los félidos y otra asexual que ocurre en félidos y en hospederos intermediarios (Soulsby, 1987). El periodo de prepatencia en los felinos depende de la fase infectante del parásito al ser ingerido, siendo de 3 a 10 días con la ingestión de quistes tisulares y de más de 18 días con la ingestión de taquizoitos u ooquistes (Dubey, 1996; Lindsay et al., 1997). La eliminación de ooquistes ocurre por 1-2 semanas y en una deyección puede haber millones de ellos.

La infección puede producirse por inhalación o ingestión accidental de ooquistes esporulados, por consumo de bradizoitos en carnes crudas o mal cocidas, o por transmisión transplacentaria de taquizoitos (Acha y Szyfres, 1992).

La mayoría de las infecciones por toxoplasmosis son asintomáticas, y como los organismos pueden infectar diversos tipos celulares, la toxoplasmosis se asocia a una gran variedad de manifestaciones, dificultando el diagnóstico clínico (Carlyle y Duncan,
1990). Los signos clínicos varían dependiendo del órgano afectado, siendo los signos más comunes la fiebre, letargia, anorexia, descargas oculares y nasales, y respiración dolorosa. Los signos neurológicos incluyen incoordinación, caminar en círculos, temblores, opistótonos, convulsiones y paresia (Jubb et al., 1990). Estudios locales sobre la presencia de anticuerpos contra este parásito han sido realizados en ovinos, cerdos y alpacas con prevalencias de $40 \%$ (Leguía et al., 1987), 50\% (Tejada y Balvín, 1989) y $44.5 \%$ (Gómez et al., 2002), respectivamente.

La toxoplasmosis es común en animales silvestres y la vía de infección no sólo es por el consumo de carne infectada o el contacto con ooquistes esporulados de los suelos, sino también por la ingestión de insectos vectores como cucarachas, moscas coprófilas, gusanos de tierra, etc., quienes actúan como hospederos de transporte (disem inación mecánica) de ooquistes fecales (Acha y Szyfres, 1992). Se produce una infección crónica, convirtiéndose en portadores potenciales para otras especies anima les y para el $m$ ismo hombre. Sin embargo, a pesar de la casi ilim itada cantidad de especies silvestres que pueden ser hospederos de este parásito, la irmensa mayoría de las infecciones son clínicamente inaparentes. No obstante, el curso clínico de la enfermedad se puede presentar como un cuadro generalizado agudo y mortal (Davis y Anderson, 1973; Borchert, 1981; Dubey, 1996). El presente estudio se realizó para determ inar la frecuencia de anticuerpos contra Toxoplasma gondii en monos Cebus apella de un zoológico de Lima.

\section{Materiales y Métodos}

\section{Lugar de estudio y animales}

El estudio se realizó en setiembre del 2003 en el zoológico del Patronato del Parque de las Leyendas, en la ciudad de Lima, Perú. Se utilizaron los 62 primates de la es- 
Cuadro 1. Frecuencia de primates Cebus apella seroreactores a Toxoplasma gondii en el zoológico del Patronato del Parque de las Leyendas (Lima, 2003)

\begin{tabular}{lccc}
\hline & \multicolumn{2}{c}{ Animales } & $\begin{array}{c}\text { Frecuencia } \\
(\%)\end{array}$ \\
\cline { 2 - 3 } & Muestreados & Positivos & \\
\hline Grupo etáreo & & & 88.9 \\
$\quad$ Juveniles & 9 & 8 & 90.6 \\
$\quad$ Adultos & 53 & 48 & \\
Sexo & & & 83.9 \\
$\quad$ Macho & 31 & 26 & 96.8 \\
$\quad$ Hembra & 31 & 30 & 90.3 \\
\hline Total & 62 & 56 & \\
\hline
\end{tabular}

pecie Cebus apella presentes en el zoológico, y que eran originarios de la región amazónica del Perú. Los animales fueron clasificados por sexo y grupo etáreo, considerando como juveniles a aquellos entre 8 a 48 meses y como adultos a los mayores de 48 meses (Rowe et al., 1996).

\section{Procesamiento y análisis de las muestras}

Se colectaron muestras de sangre a través de la punción de la vena femoral. El suero resultante se guardó en congelación a -20 ${ }^{\circ} \mathrm{C}$ hasta la realización de la prueba diagnóstica. Se determinó la presencia de anticuerpos contra Toxoplasma gondii mediante la técnica de hemaglutinación indirecta (HAI), usando el kit comercial TOXOTESTHAI (Wiener Lab, 2000) que detecta IgG. La técnica se basa en la propiedad que tienen los anticuerpos anti-Toxoplasma gondii de producir aglutinación en presencia de glóbulos rojos sensibilizados con antígenos citoplasmáticos y de membrana del parásito. Se consideraron como positivos los valores $\geq 1$ / 16 (punto de corte). No se realizó una prueba de HAI con mercaptoetanol para poder determinar la presencia de una infección aguda.

\section{Análisis de datos}

Los resultados se expresaron en porcentaje teniendo en cuenta la positividad de los sueros a la prueba serológica. Se usó la prueba de Chi Cuadrado para evaluar la asociación entre animales reactores a toxoplasmosis y las variables sexo y edad.

\section{Resultados}

El 90.3\% (56/62) de los monos Cebus apella fueron positivos a la prueba de HAI. La mayor parte de los animales seropositivos tuvo títulos de anticuerpos $\geq 1 / 256$. No se encontró diferencia significativa $(\mathrm{p}>0.05)$ en relación a la edad o al sexo (Cuadro 1)

\section{Discusión}

El elevado porcentaje de animales positivos en el zoológico del Patronato del Parque de las Leyendas contrasta con resultados obtenidos en el Centro de Reproducción y Conservación de Primates No Humanos (C.R.C.P.) del Centro de Investigaciones 
IVITA, en Iquitos, donde se reporta el 28 y $41 \%$ de primates del género Aotus positivos a anticuerpos contra T. gondii (Samamé etal., 1995; Montoya et al., 2000, respectivamente), en tanto que los sueros de las especies Saguinus mystax, Saguinus fuscicollis y Saimiri sciureos dieron resultados negativos.

La alta positividad encontrada en el presente trabajo podría deberse a diversos factores que favorecen la transmisión del protozoo. Entre ellos se encuentra la gran cantidad de roedores y gatos que merodean libremente en los alrededores de los ambientes asignados a los primates. Los roedores podrían ser ingeridos por los monos, mientras que los gatos estarían contaminando el suelo con heces que contienen los estadios infectivos de $T$. gondii, que unidas a las condiciones ambientales existentes en el zoológico, como humedad relativamente alta y una temperatura que fluctúa entre los 14 y $25^{\circ} \mathrm{C}$, proporcionan las condiciones que favorecen el desarrollo y supervivencia de los ooquistes del parásito, incrementando el riesgo de infección.

Si bien la alimentación de estos animales es controlada y está constituida a base de frutas, carne de pollo, huevo, larvas de escarabajos (tenebrios) y algunas verduras servidas en bandejas, no puede evitarse que los primates tomen contacto con ooquistes por medio de fomites o vectores, ya sean estos insectos, aves y roedores, los cuales son tomados como alimento ocasional, permitiendo una rápida diseminación del parásito.

Se ha logrado la infección experimental con $T$. gondii en primates del nuevo mundo como los monos lechuza (Aotus sp) y dos especies de Callitrichidos (Saguinus sp). causándoles la muerte. Se ha reportado infección natural en Cébidos, incluyendo animales de los géneros Allouatta, Aotus, Ateles, Cacajao, Callicebus, Cebus, Lagothrix, Pithecia y Saimiri. Muchos de estos casos fueron reportes de zoológicos donde la fuente de contagio se realizó a través de la dieta, ocurriendo la muerte de los primates sin sig- nos evidentes ni problemas de tipo reproductivo (Varela, 2001).

En el Parque Zoológico de Medellín, Colombia, se ha reportado prevalencias de anticuerpos IgG para $T$. gondii de $41 \%$ en Cebus albifrons, $13 \%$ en Cebus capucinus y $0 \%$ en C. Apella (Cadavid et al., 1991) lo que dista considerablemente de la frecuencia obtenida en el presente trabajo, posiblemente debido a que en dicho estudio tampoco se reportó la presencia de felinos libres en el parque. Así mismo, en otro estudio se observaron muertes súbitas en un grupo de primates Saimiri sciureus, evidenciándose por histopatología la presencia del parásito en los tejidos de estos animales (Varela, 2001).

Los animales silvestres mantenidos en cautiverio son más susceptibles a sufrir de diversas dolencias y adquirir con mayor facilidad cualquier enfermedad de agentes oportunistas que se encuentren en el ambiente (Davis y Anderson, 1973; Varela, 2001). Sin embargo, en el caso de la toxoplasmosis los signos no son fácilmente percibidos, o como en el caso de los humanos, los síntomas pueden ir desde una fiebre leve y diarrea ocasional hasta procesos de mayor gravedad como abortos o lesiones manifiestas en el recién nacido, los cuales son el resultado de una primo infección (Carlyle y Duncan, 1990).

En el presente estudio, a pesar del elevado número de animales positivos a $T$. gondii, ninguno mostró signos clínicos compatibles con la toxoplasmosis. La ausencia de abortos pudo deberse a que la infección se realizó a edades tempranas, antes de entrar a la edad reproductiva, lo que habría generado anticuerpos específicos contra este agente. Así mismo, es posible que alguno de los animales del estudio que llegaron al parque en una edad avanzada haya contraído la infección con anterioridad.

La prueba de HAI reconoce la Ig G, que en caso de una infección por $T$. gondii se mantiene elevada persistentemente durante 
años, de allí que la proporción de positivos $(89.3 \%)$ a títulos de $1 / 256$ no es indicativo de que la parasitosis se encontraba en la fase aguda en el momento del muestreo, pero si indica que estos primates tuvieron contacto con este agente en algún momento de sus vidas.

\section{Conclusiones}

- La frecuencia de Toxoplasma gondii en primates Cebus apella del Patronato del Parque de las Leyendas en la ciudad de Lima determinada por la prueba de HAI fue de $90.3 \%$, no hallándose asociación estadística significativa entre las variables sexo y grupo etáreo con los resultados de la serología ( $p>0.05)$.

- $\quad$ El alto número de animales positivos se debe probablemente a la presencia de felinos domésticos que deambulan por sus instalaciones, así como roedores y vectores que se encuentran en el parque y que de manera directa o indirecta pueden transmitir la toxoplasmosis.

\section{Literatura Citada}

1. Acha, P.; B. Szyfres. 1992. Zoonosis y enfermedades transmisibles comunes al hombre y a los animales. $3^{a}$ ed. $p$ 646657. OPS. Washington, EEUU.

2. Atías, A. 1994. Parasitología clínica. $3^{\mathrm{a}}$ ed. p 269-282. Ed. Mediterráneo. Chile.

3. Borchert, A. 1981. Parasitología veterinaria. $3^{a}$ ed. p 656-663. Ed. Acribia. España.

4. Cadavid, A.; L. Canas; J. Estrada; L. Ramírez. 1991. Prevalence of antiToxoplasma gondii antibodies in Cebus spp. in the Santa Fe Zoological Park of Medellin, Colombia. J. Med. Primatol. 20: 259-261.

5. Carlyle, T.; R. Duncan. 1990. Patología veterinaria. Vol. II. p 734-740. Ed. Hemisferio Sur. Argentina.
6. Davis, J.; R. Anderson. 1973. Enfermedades parasitarias de los mamíferos salvajes. p 326-329. Ed. Acribia. Zaragoza, España.

7. Dubey, J. 1996. Infectivity and pathogenicity of Toxoplasma gondii oocysts for cats. J. Parasitol. 82: 957961.

8. Gómez, F.; A. Chávez; E. Casas; E. Serrano; O. Cárdenas. 2002. Determinación de la seroprevalencia de toxoplasmosis en alpacas y llamas en la Estación Experimental INIA-Puno. Rev. Inv. Vet., Perú 14: 49-53.

9. Jubb, K.; P. Kennedy; N. Palmer. 1990. Patología de los animales domésticos. $3^{\mathrm{a}}$ ed. Vol. II. p 235-238. Ed. Hemisferio Sur. Uruguay.

10. Leguía, G.; C. Guerrero; P. Dionisio. 1987. Toxoplasma gondii en borregas abortadas y mortalidad de crías. Rev. Cienc. Vet. Perú 3: 23-25.

11. Lindsay, D.; B. Blagburn; J. Dubey. 1997. Feline toxoplasmosis and the importance of the Toxoplasma gondii oocyst. Parasitology 19: 448-461.

12. Montoya, E.; C. Ique; H. Samamé; A. Romaina. 2000. Seroprevalencia de Toxoplasma gondii en Aotus vociferans (Primates: Cebidae) en cautiverio. Rev. de Cienc. Vet. Perú 16: 2224.

13. Rowe, N.; J. Goodall; R. Mittermeier. 1996. The pictorial guide to the living primates. p 127-128. Ed. Pogonias Press. New York, USA.

14. Samamé, H.; A. Gozalo; E. Montoya; E. Villavicencio; A. Romaina; J. Moro. 1995. Anticuerpos contra Toxoplasma gondii en primates neotropicales. Rev. Cienc. Veter. Perú 3: 5-8.

15. Soulsby, L.E.J. 1987. Parasitología y enfermedades parasitarias en los animales domésticos. 7 ed. p 681-685. Ed. Interamericana. México.

16. Tejada, A.; G. Balvín. 1989. Situación actual del estudio de toxoplasmosis en el Perú. Anales del Seminario Nacional de Zoonosis y Enfermedades de Transmisión Alimentaria. p 107-121. Perú. 
17. Varela, N. 2001. La toxoplasmosis en los primates del Nuevo Mundo. Boletín GEAS. Vol 2. Disponible en: www.geocites.com/urras geas/boleti$\underline{\text { nes/2001/010204.htm }}$
18. Wiener Lab. Toxotest HAI. 2000. Prueba de hemaglutinación indirecta (HAI) para la detección de anticuerpos contra el Toxoplasma gondii. Rosario, Argentina. $2 \mathrm{p}$. 